\title{
Syntax and its interfaces at the low and high ends of the autistic spectrum
}

Book or Report Section

Accepted Version

Terzi, A., Marinis, T. and Francis, K. (2016) Syntax and its interfaces at the low and high ends of the autistic spectrum. In: Di Sciullo, A. M. (ed.) Biolinguistic Investigations on the Language Faculty. Linguistik Aktuell/Linguistics Today (235). John Benjamins, pp. 195-212. ISBN 9789027257185 doi: https://doi.org/10.1075/la.235.09ter Available at http://centaur.reading.ac.uk/68299/

It is advisable to refer to the publisher's version if you intend to cite from the work. See Guidance on citing.

To link to this article DOI: http://dx.doi.org/10.1075/la.235.09ter

Publisher: John Benjamins

All outputs in CentAUR are protected by Intellectual Property Rights law, including copyright law. Copyright and IPR is retained by the creators or other copyright holders. Terms and conditions for use of this material are defined in the End User Agreement. 


\section{www.reading.ac.uk/centaur}

\section{CentAUR}

Central Archive at the University of Reading

Reading's research outputs online 
In A. M. Di Sciullo (ed.) 2016. Biolinguistic Investigations on the Language Faculty, 000000, Amsterdam: John Benjamins

\title{
SYNTAX AND ITS INTERFACES AT THE LOW AND HIGH ENDS OF THE AUTISM SPECTRUM
}

\author{
Arhonto Terzi ${ }^{1}$, Theodoros Marinis ${ }^{2}$, Kostantinos Francis $^{3}$ \\ ${ }^{1}$ Technological Educational Institute of W. Greece, Patras, ${ }^{2}$ University of Reading, \\ ${ }^{3}$ University of Athens
}

Corresponding author

Arhonto Terzi

Department of Speech and Language Therapy

Technological Educational Institute of W. Greece, Patras

aterzi@teipat.gr, arhonto.terzi@gmail.com

Abstract 
Studies on the language abilities in autism spectrum disorders (ASD) have tended to include individuals across the spectrum, with the consequence that the ensuing picture is rarely clear. Most recent studies setting apart individuals at the lower end of the autism spectrum have discovered severe problems in certain areas of grammar.

Investigation of grammatical abilities at the higher end of the spectrum has not identified severe problems so far, in an interesting contrast with the lower end. Here we report on current research on pronominal object clitics and their counterpart DPs, which demonstrates that, in some syntactic environments, high-functioning children with ASD fall behind typically developing children. We claim that this behavior does not reflect problems with syntax proper, but is a consequence of pragmatic shortcomings with consequences for the syntax-pragmatics interface. Errors of substitution of clitics with their corresponding DPs are likely to be caused by difficulties in detecting prominence in the discourse. Difficulties with Focused DPs are likely to be caused by problems in distinguishing old from new information and its mapping to prosody. Future research needs to investigate pragmatics, syntax and prosody independently, in order to reach solid conclusions regarding their interaction with respect to specific phenomena in autism, which, in turn, provides an ideal condition to test the contribution of each domain to these phenomena. 


\section{Introduction}

Research on the language of individuals with autism spectrum disorders (ASD) has addressed whether there are particular properties that characterize their language abilities, but has focused primarily on pragmatics and prosody, domains that were traditionally known to be associated with problems in autism (see Diehl et al. 2009, Landa 2000, Surian et al. 1996, Tager-Flusberg et al. 2005, and references therein). In contrast, studies addressing the morphosyntax of individuals with ASD are still relatively scarce. This is much more the case for studies that investigate the interface of morphosyntax with pragmatics and/or prosody, with the consequence that it is unclear to a large extent how the latter impact on the former in individuals with ASD. Finally, studies on the language abilities of individuals with ASD have been primarily concerned with issues pertaining to English-speaking populations and the English grammar.

The relative scarcity of studies of the grammatical abilities in ASD is complicated by two addition factors. First, ASD is a spectrum, and, as a consequence, there is large variability in the profile of individuals. Second, some individuals with ASD may also be comorbid with Specific Language Impairment (SLI). A number of studies have in fact been preoccupied with how the grammatical abilities in ASD differ from those in SLI (Roberts et al. 2004 among others).

This paper addresses aspects of the morphosyntax of high-functioning children with ASD, namely, children with ASD who score like typical populations in general language and cognitive tasks. In section 2 it presents evidence from previous studies and discusses the role of the high vs. low ends of the spectrum in the language profile of the children. Section 3 focuses on the acquisition of binding of pronouns, reviewing previous research. Binding involves syntax proper, but, depending on the task used and the pronouns tested, it may also involve pragmatics. Section 4 focuses on our own studies of high-functioning children with 
ASD, and discusses their performance on phenomena that involve syntax proper compared to phenomena at the interface of syntax with pragmatics and prosody.

2. Effects of high- vs. low-functioning on morphosyntactic abilities

A first complete and well-informed study of morphosyntax in autism is the one conducted by Roberts et al. (2004). The authors divided the participants of their study into three groups, based on their performance on the Peabody Picture Vocabulary Test III (PPVT: Dunn \& Dunn 1997) that measures the comprehension of single-word vocabulary. Group I had PPVT scores within the normal range, that is, 85 and higher, Group II had PPVT scores between 1 and 2 standard deviations from the mean, that is, between 70 and 84, and Group III had PPVT scores below 2 standard deviations. All children of Group I had non-verbal IQ within the normal range, while this was the case in less than half of the children of Group II and only 4 out of the 19 children of Group III. The study investigated the use of third person singular $-s$ and regular past tense -ed in English, the former being well known to constitute a clinical marker for SLI. They found that the scores of Group 3 were worse than those of children with SLI of the same language (verbal IQ) range. However, the children with SLI were within norms in terms of non-verbal IQ, whereas the majority of the children with ASD had nonverbal IQ below the normal range. These results indicated that low-functioning children with ASD have deficits in morphosyntax and perform less well than children with SLI whose language is characterized by deficits in grammar. Moreover, it highlights the importance of matching groups in terms of non-verbal abilities, even when the groups are matched for their verbal abilities.

A similar outcome emerges from two recent studies of another domain of English grammar, the comprehension of pronouns (Perovic et al. 2013a, b). Perovic et al. (2013a) studied Binding Principles A and B of children with ASD. The participants with ASD of their 
study had low language and non-verbal abilities and were matched with two groups of TD children, one on language abilities and the other one on non-verbal IQ. Individuals with ASD were found to perform more or less like the control groups on binding of personal pronouns, but significantly lower on binding of reflexive pronouns, an area that is not known to present problems in early language. This finding was important precisely because it had the potential of identifying an area of grammar that is not expected to be found impaired, since we do not have instances of either earlier grammar, or some other pathology in which children fall behind on assigning the appropriate antecedent to a reflexive pronoun (with the exception of Down syndrome, see below). Hence, the specific finding had the potential of qualifying as a fundamental characteristic of the linguistic phenotype of individuals with ASD.

In a follow up study, Perovic et al. (2013b) found that things were a bit more complex. The participants of this study were divided into two groups: those with ASD and language impairment (ALI) and those with ASD and normal language (ALN), as assessed by standardized measures of vocabulary and grammar. The result was, again, that performance on binding of reflexive pronouns was low, but only for the ALI group. Interestingly, the majority of the children with low language abilities in this study also had low non-verbal abilities. The authors claim that low non-verbal abilities alone cannot be responsible for the poor performance on binding of reflexives for two reasons: first, because, although reflexive pronouns are impaired in individuals with Down's syndrome, a syndrome which is characterized by extensive language delay and low non-verbal IQ (Perovic 2006), a group of children with Williams syndrome with equally low non-verbal IQ as the ALI children of the Perovic et al. (2013b) study did not demonstrate a similar weakness on reflexives; second, because the TD controls that were matched to the ALI group on non-verbal reasoning did not have low performance on reflexives either. Therefore, despite the fact that it has been pointed out that children with ASD and low non-verbal IQ show a more delayed language 
than those who are high-functioning (Boucher 2009), low-functioning alone is not in a position to explain why there is a deficit in specific domains of grammar. Moreover, it is difficult to estimate the contribution of non-verbal abilities to deficits on reflexives in some precise manner. Nevertheless, it is clearly the case that Perovic et al. (2013a, b) identified an impaired domain of grammar associated with the lower end of the autism spectrum, regardless of whether the reasons for this association are well understood. ${ }^{1}$

If detecting weaknesses in the (morpho)syntax of individuals who are in lower range of the autism spectrum is valuable, it is equally important to investigate the characteristics of (morpho)syntax in children within the higher end of the spectrum. This will enable us to identify specific areas of grammar that present challenges for this group of individuals with ASD. ${ }^{2}$ We already reported that English speaking ALI children differ from ALN children on reflexives, with the latter demonstrating the behavior of the TD controls. One wonders, however, whether other aspects of morphosyntax are affected in high-functioning children with ASD and how high-functioning children with ASD compare to TD children in terms of grammatical development. If high-functioning children with ASD have deficits in specific domains of grammar, these would also be candidates for deficits associated with ASD and their source should be investigated. In our published and ongoing research, we tackle precisely these issues.

\footnotetext{
${ }^{1}$ However, one cannot disregard that although the group of the ALI children with ASD and the group of the children with Williams syndrome of the study were matched on age and non-verbal intelligence, the overall language abilities of the ALI children in terms of vocabulary and grammar were much lower than those of the children with Williams syndrome.

2 This is actually the aim of the study of Janke and Perovic (2015) who did not detect weaknesses specific to the high-functioning children with autism in control structures.
} 
3. Binding of pronouns: syntax proper and its interface with pragmatics and prosody

\subsection{Reflexive pronouns}

The finding of Perovic et al. (2013a) that children with ASD demonstrate a weakness on the binding of reflexive pronouns in English was the initial source of our motivation to investigate how Greek-speaking children with ASD perform on binding of reflexive pronouns (Terzi et al. 2014). There were several reasons for being particularly motivated to undertake the study. First, because Greek reflexive pronouns have strikingly different properties from the reflexive pronouns of English, as discussed in much detail by Anagnostopoulou and Everaert (1999), and can probably be inferred even after a superficial look at their form, (1a). Furthermore, in addition to employing reflexive pronouns, reflexivity in Greek can also be expressed by means of non-active morphology on the verb, (2b).

(1) a. John loves himself.

b. O Yianis agapa ton eafto tu. the John loves the self his 'John loves himself.'

(2) a. John is shaving himself.

b. O Yianis xsirizete the John shaves-non-active 'John is shaving himself.'

The participants in the study of Terzi et al. (2014) were 20 high-functioning children with ASD, individually matched with TD children of similar age on a vocabulary task modelled after the PPVT. Ages of both groups ranged between 5 and 8 years old, with mean age 6;08 
and 6;09 for ASD and TD respectively. We decided to start by focusing on a narrow age range in order to avoid confounds due to different developmental trends in the two groups. Children of both groups had average or above average PPVT and Raven's scores (mean Raven's and vocabulary scores for ASD: 103.5 and 102.3 respectively, mean Raven's and vocabulary for TD: 98.0 and 102.7 respectively). The children were tested on binding of reflexive pronouns, but also on binding of object personal pronouns and of object clitic pronouns. The task employed was a picture selection task that used three pictures for each of the sentences assessed.

We found that children with ASD performed well on reflexives. This was a surprise at the time, and several reasons for this discrepancy were considered since it was not until sometime later that the Perovic et al. (2013b) study came out and clarified that, even among English-speaking children with ASD, only the low-functioning have trouble with binding of reflexives. The children in our study were high-functioning and with typical overall language abilities, as assessed by the vocabulary task on the basis of which they were matched and a morphosyntax task (DVIQ, Stavrakaki \& Tsimpli 2000). However, three children who took part in the study could not be included in the sample of the 20 high-functioning children, because their Raven's score was low and they did not meet the selection criteria of high functioning children with ASD. Precisely these three children performed much worse on binding of reflexives than the high-functioning children included in the study of Terzi et al. (2014), to which we return in detail immediately below. The sample is too small to allow us to draw firm conclusions, but given the findings in Perovic et al. (2013b), it is worth reporting and definitely worth confirming in a future study with a larger sample.

\subsection{Personal pronouns}

As already mentioned, the study of Terzi et al. (2014) also assessed the reference of personal 
pronouns, both strong forms, (3a), and clitics, (3b), that is, the knowledge of Principle B of Binding Theory, (3). ${ }^{3}$

(3) a. I Maria zografizi aftin.

the Mary paints her-full pronoun

b. I Maria tin zografizi.

the Mary her-clitic pronoun paints

'Mary is painting her.'

The only domain in which children with autism fell behind their TD controls in this study was on binding of clitic pronouns, an area of grammar that is known to be mastered early by TD Greek-speaking children (Varlokosta 2000). Since this is the domain on which this paper will primarily focus, we present in Table 1 below the actual results.

Table 1: Accuracy on binding (comprehension) of pronouns (Terzi et al. 2014)

\begin{tabular}{|l|l|l|l|}
\hline & Reflexive pronouns & Strong pronouns & Clitic pronouns \\
\hline ASD & $97.5 \%$ & $94.9 \%$ & $88.3 \%$ \\
\hline TD & $99.2 \%$ & $93.3 \%$ & $99.2 \%$ \\
\hline
\end{tabular}

Table 1 shows that, although children with ASD performed significantly worse than the TD controls on clitic pronouns, their performance was not very low. This raises some first doubts

\footnotetext{
${ }^{3}$ The study also investigated comprehension of passive sentences, which turned out to be low (around 70\% correct responses), but for both groups of children. Perovic et al. (2013b) report, from Perovic et al. (2007), that English-speaking children with autism performed low on passives, but do not clarify at which part of the spectrum these children were.
} 
over whether the problem high-functioning children with ASD have with binding of object clitic pronouns is strictly a syntactic one.

In a follow up study, we assessed production of clitics of the same children and their typical TD controls, using the elicitation task of Chondrogianni et al. (2015). In this task, two characters are introduced in one picture, (4a), and, in a subsequent picture, participants are asked to respond on what one of the characters did to the other, (4b). The target answer to such a question is a VP containing the object, since the verb is transitive. Because the object was mentioned in the eliciting question, the felicitous answer should contain a clitic rather the corresponding DP, (5).

(4) a. Edo exume enan liko ki enan elefanda.

Object clitic here we-have a wolf and an elephant

b. Ti kani o likos ston elefanda?

Eliciting question what does the wolf to the elephant

(5)

Ton filai.

Target answer him-clitic kisses '(he) kisses him.'

Sixteen out of the 20 children of the initial study, along with their matched controls, participated and the results showed that the children with ASD fell behind on the production of clitics, although, again, not by far behind the TD controls. 
Table 2: Accuracy on production of clitics (Terzi et al. 2014)

\begin{tabular}{|l|l|l|l|}
\hline & Clitics & DPs & Omissions \\
\hline ASD & $87.39 \%$ & $5.27 \%$ & $7.34 \%$ \\
\hline TD & $97.74 \%$ & $2.26 \%$ & $0 \%$ \\
\hline
\end{tabular}

Before discussing the breakdown of the production errors, we will call attention to the comprehension errors, since they were the ones that motivated the study to be discussed in much of what follows. The predominant error type in the comprehension task (10 out of 14 errors), Table 1, was that children interpreted sentences such as (3b), as one on which Mary was the patient, rather than the agent. The hypothesis we entertained in order to explain this behavior, hence the weakness on the comprehension/binding of object clitics as well, was that the children with ASD interpreted sentences such as (3b), as Clitic Left Dislocation structures (CLLD), (6).

Ti Maria ti zografizi.

the Mary, her-clitic pronoun paints

'As for Mary, (she/he) paints her.'

4. Object clitics and their counterpart DPs in high-functioning autism

A consequence of the previous findings was that they motivated a new study, which investigated how high-functioning children with ASD interpret sentences such as (6) above, and how this compares to their interpretation of sentences with simple clitics, such as in (3b). In order to do so, we did not only assess comprehension and production of simple clitics, but also comprehension and production of clitics in CLLD structures, along with a number of other structures that forbid the use of a clitic pronoun (Terzi et al. 2015). The use of clitic 
pronouns, by contrast to their corresponding DPs, is determined on the basis of specific pragmatic grounds, which are rather well described in the relevant literature - see Mavrogiorgos (2010) for a recent review, and the discussion later in the paper. Such a study, therefore, would provide the opportunity to investigate whether morphosyntax of children with ASD is indeed affected by deficits in pragmatics and how, a finding of much interest given that we are dealing with a population widely held to fall behind in pragmatics.

The study of Terzi et al. (2015) focused on a new group of 20 high-functioning children of a very similar age group as the one in Terzi et al. (2014). The mean age of the ASD group was $6 ; 11$ and that of their TD controls was 6;07. The latter were matched individually with the children with autism on the PPVT vocabulary test (adaptation for Greek: Simos et al. 2011), and children of both groups had to score above 80 on the Raven's test in order to be included in the study. Both groups were tested on comprehension (binding) of pronominal clitics, and production of clitics. Moreover, they were also tested on comprehension and production of CLLD structures, that is, of structures as in (6). Comprehension and production of clitics was assessed as in the previous study. Comprehension of CLLD was assessed just as comprehension of (simple) clitics, that is, by using a picture pointing task via which children had to select from a set of three pictures each time. Production of CLLD was tested via a sentence completion task with the use of two pictures. The first picture showed three animal characters who were identified for the children, (7a). The experimenter subsequently asked a question pertaining to the action of one of the three animals to another and started answering the question himself by using a DP. The child had to complete the answer, and, crucially, the felicitous answer had to include a clitic, (8), hence, end up in a CLLD structure: 
(7) a. Edo exume mia gata, enan liko ke mia katsika.

here we-have a cat, a wolf and a goat.

b. Pios filai ti gata? Ti gata ...

Eliciting question

who kisses the goat? The goat ...

'Who kisses the goat? As for the goat ...

(8)

... $t i$ filai o likos.

Target answer

her-clitic kisses the wolf

the wolf kisses her.'

In addition to CLLD, we investigated another structure, which looks similar to it at the surface, in the sense that it also starts with an object DP displaced in sentence initial position. This was a Focus structure, in which the object of the target sentence is Focused, therefore, no clitic is allowed to double it (Cinque 1997, a.o.). An additional difference between CLLD structures and Focus structures is that the object DP that starts the sentence in the Focus structure bears a particular Focus accent, indicated with upper case letters. The two structures also differ in that the Focus structure refers to new information, while the CLLD to old information, hence the use of the clitic pronoun, that is, of an element that needs to refer to something that has been mentioned in the discourse in order to be felicitous (Anagnostopoulou 1997, Cinque 1997, Rizzi 1997). The Focus task was a sentence completion task that employed two pictures as well. The experimenter presented the animals in the first picture, (9a), and then asked a question which he started to answer with a DP with Focus accent, (9b). The participants had to continue the answer with a sentence such as in (10), crucially not using a clitic. 
(9) a. Edo exume ena liondari, mia arkuda ki enan elefanda.

Focus here we-have a lion, a bear and an elephant.

b. Pion filai i arkuda? TON ELEFANDA ... Eliciting question who kisses the bear? THE ELEPHANT

'Who does the bear kiss? It is the elephant ...

(10) ... filai i arkuda.

Target answer

kisses the bear

that the bear kisses.'

Finally, we also elicited answers to questions that do not allow for the use of a (simple) clitic, but require the corresponding DP, (12). These DPs were elicited via two conditions, condition DP1 and condition DP2. In both conditions, the same question was asked, (11c), but the sentence that introduced the characters in the pictures was different, cf. (11a) and (11b). Just like when eliciting clitics, the answer to the eliciting question requests the use of a VP. However, because the object DP is not mentioned in the eliciting question, hence, it is not prominent in the immediately preceding discourse, the felicitous response does not allow for the use of a clitic, but requires the DP, (12).
a. Edo exume ena liondari ki ena elafi.
DP1
here we-have a lion and a deer
b. Des edo!
DP2
Look here! 
c. Ti kani to liondari?

what does the lion

'What does the lion do?'

(12)

Dagoni to elafi.
Eliciting question

(DP1, DP2)

Target answer

bites the deer

'(he) bites the deer.'

Thus, by comparing (11a) and (11b), we can see that in condition DP1 the characters of the picture, i.e., the lion and the deer, were introduced to the participants, while in condition DP2 they were not. Instead, in condition DP2 the participants were just asked to look at the characters in the picture. We report below the results from all experiments as well as the error analyses for the conditions that need to be further discussed. The columns with the stars are the only ones in which there was a significant difference between the two groups.

Table 3: Accuracy on binding (comprehension)

\begin{tabular}{|l|l|l|}
\hline & Clitics * & CLLD \\
\hline ASD & $94.2 \%$ & $86.3 \%$ \\
\hline TD & $100 \%$ & $91.7 \%$ \\
\hline
\end{tabular}

Table 4: Accuracy on production

\begin{tabular}{|l|l|l|l|l|l|}
\hline & Clitics * & CLLD & Focus * & DP1 & DP2 \\
\hline ASD & $82 \%$ & $85.7 \%$ & $71.5 \%$ & $52.3 \%$ & $91.5 \%$ \\
\hline TD & $97.5 \%$ & $95.3 \%$ & $88.9 \%$ & $35.4 \%$ & $89.8 \%$ \\
\hline
\end{tabular}


Table 5: Error analysis in the production of clitics

\begin{tabular}{|l|l|l|l|}
\hline & Clitics & DPs & Omissions \\
\hline ASD & $82 \%$ & $12 \%$ & $6 \%$ \\
\hline TD & $97.5 \%$ & $2,5 \%$ & $0 \%$ \\
\hline
\end{tabular}

Table 6: Error analysis in the production of Focus structure

\begin{tabular}{|l|l|l|l|}
\hline & Production of clitics & No sensitivity to context & Other \\
\hline ASD & 15 & 10 & 3 \\
\hline TD & 4 & 2 & 3 \\
\hline
\end{tabular}

Table 7: Error analysis in the production of DP1

\begin{tabular}{|l|l|l|l|}
\hline & Production of clitics & Omission of DP & Other \\
\hline ASD & 50 & 4 & 2 \\
\hline TD & 75 & 1 & 0 \\
\hline
\end{tabular}

Table 8: Error analysis in the production of DP2

\begin{tabular}{|l|l|l|l|}
\hline & Production of clitics & Omission of DP & Other \\
\hline ASD & 3 & 4 & 3 \\
\hline TD & 8 & 3 & 0 \\
\hline
\end{tabular}

The two groups differed significantly from each other only on the comprehension and production of clitics and on the production of Focus structures, that is, on the cells of Tables 3 and 4 that are marked with a star. Let us start by noting that in both studies, namely, the current one and the one by Terzi et al. (2014), Greek-speaking high-functioning children with ASD differed from TD children on both comprehension and production of simple clitics, 
moreover, they differed in a very similar manner quantitatively. This shows that the findings are replicable and indicates that we are dealing with an area of morphosyntax, in which highfunctioning ASD children indeed fall behind TD children, although not by far as comparison of the actual results confirms.

Does the difficulty that children with ASD have in comprehending and producing object clitics relate to deficits in syntax proper? Let us start with production: the most common error among children with ASD in the production of clitics task of the current study was to use a DP instead of a clitic, see Table 5. We believe they commit this error because they are not entirely in compliance with the condition that allows for the use of a clitic. As claimed by Anagnostopoulou (1999) and Mavrogiorgos (2010), among others, a clitic refers to an entity that has been mentioned in the immediately preceding discourse, hence, has become not only familiar, but also prominent. In other words, in their use of object clitic pronouns, people make use of the Prominence Condition of Heim (1982), according to which a pronoun refers to a prominent element in the discourse. If Greek-speaking children with ASD do not produce clitics, it means, either that they do not know the Prominence Condition and the fact that it regulates the use of clitics, or that they know it but cannot always tell what is the prominent element in the discourse. Do we have independent evidence to this effect? Not really from the children of our study. It is known, however, that individuals with autism do not have good awareness of salience in their environment (Landa 2000). If this property carries over to language, it can be considered to correspond to a pragmatic condition that does not allow children to attain full mastery of the use of clitics as a consequence of not being able to distinguish the salient element in the discourse. We are led to conclude that the children with ASD, at least the high-functioning children of our study, fail to distinguish the prominent element in the discourse, rather than ignore the Prominence Condition altogether, because their error rate on the production of promominal object clitics is higher than that of 
TD children but it is not extremely high. This pragmatic factor can presumably also account for the mild weakness attested in Terzi et al. (2014), Table 2, according to which about half of the errors in the production of clitics consisted of replacing the clitic with the full DP.

How about the conditions that elicited full DPs? As mentioned earlier, two conditions elicited object DPs (and did not allow for the use of the corresponding object clitic). The two conditions differed from each other with respect to the part that introduced the characters in the pictures that were used, right before asking the question that aimed at eliciting a DP. In condition DP1 the characters were introduced upon showing the picture that contained them, (11a). In condition DP2 the characters were not introduced; instead, the picture with the characters was shown to the participants asking them to just look at it, (11b). The two groups, ASD and TD, did not differ significantly from each other on either condition. However, there are two important observations : First, both groups did extremely low on condition DP1, by contrast to condition P2. The overwhelming majority of errors for both groups involved use of a clitic, rather than the (felicitous) DPs. Second, the children with ASD did much better than the TD children on condition DP1, although this difference did not reach statistical significance. We believe that the much worse performance of both groups on DP1, which essentially consisted in using clitics rather than the corresponding DPs, was due to the fact that the characters of the story had been introduced, by sentence (11a), hence, the children were already familiar with them and were able to refer to them via a clitic, ignoring that they actually had to respond to a specific question, (11c), which did not include any of the characters, hence, did not allow for the use of clitics. We believe that the children with ASD did slightly better than the TD children on this task precisely because they were able to follow instructions better, that is, to focus on what the particular sentence was asking them to do, that is, consider question (11c) as the relevant discourse for the use of the DP. All in all however, the contrast between condition DP1 and DP2 shows that the high-functioning 
children with ASD have a fairly good knowledge of the rules, according to which you cannot refer with a clitic to something not mentioned in the discourse, and this accounts for their good performance on DP2. This offers further support to our earlier claim about the production of simple clitics, namely, that children with ASD cannot always tell the prominent element in the discourse, rather than not being of the Prominence Condition and that it regulates the distribution of clitics.

Let us now proceed to the results on CLLD. This condition showed that the two groups did not differ significantly from each other and they also did not differ significantly from the simple clitics production task either. Regardless of how exactly a CLLD structure, (6), differs from a structure with a simple clitic, (3b), it is definitely the case that the former is syntactically more complex than the latter: for one thing, CLLD involves a chain that connects the DP in sentence initial position and the clitic. This is a predicate variable chain according to Anagnostopoulou (1997), and it is reasonable to assume that it results in a syntactically more complex structure when compared to a structure that contains just a clitic. Since the two groups of children do not differ, and neither group differs significantly from the simple clitics task, we believe we have a clear indication that syntactic complexity per se does not affect the high-functioning children with ASD disproportionally. This amounts to saying that we have not found so far a problem with syntax proper in the high-functioning group of children we tested. By contrast, the problems detected so far are most likely associated with the syntax-pragmatics interface. Such was the case with the production of clitics, and we believe it also holds for what is to be discussed immediately below.

The last structure that remains to be discussed is (production of) Focus, the other structure on which ASD children were found to perform at a significantly lower rate than their TD controls, see Tables 4 and 6. The structure is similar to CLLD in the sense that it also contains a DP that is displaced to the beginning of the sentence. On the other hand, as 
already mentioned, it differs in three important ways from CLLD: a) no clitic is or may be employed to double the DP at the beginning of the sentence, $b$ ) the DP at the beginning of the sentence refers to new information, and c) the DP at the beginning of the sentence bears Focus accent (Keller \& Alexopoulou 2001). The majority of errors of children with ASD on this condition involved the use of a clitic, which as we have repeated, is ungrammatical in Focus structures. One may be tempted to think that the children with ASD do not perceive the different intonation associated with a Focused DP, and, as a consequence, they disregard the rest of the properties of the structure associated with it.

Evidence from other studies indicates that this may not be the case for two reasons: first, the recent study of Diehl et al. (2015) has offered convincing evidence, that, although prosody is a domain of language that is impaired even in high-verbal children with autism, these children do not have difficulties using prosody in order to determine the syntactic structure of a linguistic expression. Second, the authors report that although prosody definitely distinguishes ASD children from TD children on (non-linguistic) pragmatic domains, such as detecting emotions, there is no evidence that it impacts on syntax, although, admittedly there are not very many studies on the topic.

We believe, therefore, that it is most likely not problems with Focus accent/intonation per se that lead the high-functioning children with ASD of our study to perform less well than the TD children on the Focus structure we tested. Instead, we believe that they do perceive that the DP has a distinct intonation, but they are not able to tell, or know, that this particular intonation is associated with a specific interpretation, that is, with new information, which, in turn, precludes the use of a clitic.

To summarize, we hold that the ASD children of our study did not do well on the Focus structure not because this is a structure associated with a particular prosody, although prosody is a domain that even high-functioning children have trouble with. Instead, their 
problem lies in the fact that, although they are able to detect a distinct prosody in Focus structures, they cannot associate it with a distinct interpretation, namely, with new information. This behavior may be related to problems children with ASD have in distinguishing between new and old information. We do not have independent evidence that the children of our study had trouble in establishing this contrast. Nevertheless, problems in distinguishing old from new information are well documented in the literature, even for highfunctioning children with autism (Diehl et al., 2006; Tager-Flushberg, 2000).

Moreover, the children of the study in Terzi et al. (2014), who were of practically the same age and had almost the same profile as the ones of the current study, had difficulties in establishing another type of contrast. Assessment of the pragmatic abilities of the aforementioned group of children via the Diagnostic Evaluation of Language Variation (DELV) (Seymour et al., 2005) has shown that the children with ASD had difficulties contrasting characters that they had to describe and present in a story (Marinis et al., 2013), despite the fact that they performed fine on mental state and false beliefs, areas that are considered particularly problematic in autism (Surian et al. 1996). A question that arises at this point is the following: if the children of the current study have difficulties distinguishing old from new information, which, in turn, cannot map the latter to a Focus accented DP appropriately, why didn't they have similar difficulties with CLLD, which stands for old information? We believe that the issue of distinguishing old from new information does not arise for CLLD for the simple reason that the sentence initial object DP offers the property that is required for the use of a clitic by simply being there, namely, by providing the prominent element in the discourse. In the Focus structure, however, this piece of information has to be inferred via the particular Focus accent, which children with ASD cannot map accordingly. 
A last observation is that, although children erroneously produced a clitic when asked to complete a Focus structure, hence, in effect they produced erroneously a CLLD structure, they never failed to employ the verb-subject order in the response sentence, see (8), which is the only grammatical order for the verb and the subject in this syntactic environment. This constitutes another piece of evidence in favor of a non-impaired syntax proper. ${ }^{4}$

\section{Conclusions and further directions}

The pattern shown in the previous section indicates that the high-functioning Greek-speaking children we assessed via two studies do not seem to have problems in syntax proper. This follows from their performance on binding of reflexive pronouns (Terzi et al. 2014), but also from their performance on CLLD when compared to performance on simple clitics (Terzi 2015). The recent study by Janke and Perovic (2015), which also studied high-functioning children, did not find problems on subject and object control either. This contrasts with the studies of Perovic et al. (2013a, b), who investigated children on the lower end of the spectrum, and discovered serious difficulties with (binding of) reflexives as well as the study of Roberts et al. (2004) on the English Tense inflection. Moreover, a careful reading of the literature on language abilities in autism reveals that whenever the individuals who are assessed appear to have problems, it is either that the high vs. low end of the spectrum has not been taken into consideration, or that the studies are not clear about where in the spectrum their participants belong. Therefore, it is safe to conclude that when individuals with ASD demonstrate impaired performance on morphosyntax, they are not high-functioning.

\footnotetext{
${ }^{4}$ Table 6 indicates that the second larger type of error ASD children commit is what we have called 'no sensitivity to context'. In this error type the children to ASD answered question (9b) without taking into account that they had to complete the answer of the experimenter. The children made the same error type also in the CLLD condition, but we did not report the breakdown of the error types of this condition because there was no difference between the two two groups.
} 
Yet, as we demonstrated, mild problems do exist in the morphosyntax of highfunctioning Greek-speaking children in structures that involve clitic pronouns. However, we claim that these problems do not reflect impaired morphosyntax. Instead, they reflect weaknesses in pragmatics, possibly along with its mapping to prosody that have consequences for the interfaces with syntax. Admittedly, there has been a caveat in our argumentation: although we resorted to a pragmatic shortcoming in order to explain the mild problems in syntax, we did so on the basis of what we knew from other studies, either on the notion of prominence or on new vs. old information in autism. In order to enhance the validity of such claims iyt is necessary to run independent experiments on these very factors with the same individuals whose morphosyntax is found mildly impaired. The same goes for prosody and Focus accent.

Until this happens, the conclusion from the studies reported here, including our own, is that problems with morphosyntax which can be attributed to syntax proper have been discovered only among low-functioning individuals with autism. The shortcomings of the grammar of the individuals on the high end of the spectrum are mild to non-existent and are, most probably, a consequence of impairments in pragmatics and the syntax-pragmatics interface, in ways that deserve further investigation. Given that some of these domains may be found impaired in autism on the basis of independent evidence, one can tell apart their contribution to the study of phenomena associated with clitics, and not only, rendering the study of language in autism even more interesting for this reason. 


\section{References}

Anagnostopoulou, E. 1997. Clitic Left Dislocation and Contrastive Left Dislocation. In Materials on Left Dislocation, E. Anagnostopoulou, H. van Riemsdijk \& F. Zwarts (eds),151-192. Amsterdam: John Benjamins.

Anagnostopoulou, E. 1999. Conditions on clitic doubling in Greek. In Clitics in the Languages of Europe, H. van Riemsdijk (ed), 761-798. Berlin: Mouton de Gruyter.

Anagnostopoulou, E. \& Everaert, M. 1999. Toward a more complete typology of anaphoric expressions. Linguistic Inquiry 30: 97-119.

Boucher, J. 2009. The autistic spectrum: Characteristics, causes and practical issues. Thousand Oaks, CA: Sage.

Chondrogianni, V., Marinis, T., Edwards, S. \& Blom, E. 2015. Production and online comprehension of definite articles and clitic pronouns by Greek sequential bilingual children and monolingual children with Specific Language Impairment. Applied Psycholinguistics 36: 1155-1191.

Cinque, G. (1997). 'Topic' Constructions in some European Languages and 'Connectedness'. In Materials on Left Dislocation,E. Anagnostopoulou, H. van Riemsdijk \& F. Zwarts (eds), 93-118. Amsterdam: John Benjamins.

Diehl, J.J., Bennetto, L. \& Young, E.C. 2006. Narrative coherence of high-functioning children with autism spectrum disorders. Journal of Abnormal Child Psychology, 34: 87-102.

Diehl, J.J., Watson, D., Bennetto, L., McDonough, J. \& Gunlogson, C. 2009. An acoustic analysis of prosody in high-functioning autism. Applied Psycholinguistics 30: 385404. 
Diehl, J.J., Friedberg, C., Paul, R., \& Snedeker, J. 2014. The use of prosody during syntactic processing in children and adolescents with autism spectrum disorders. Development and psychopathology, X: 1-18.

Dunn, L.M., \& Dunn, D. M. 1997. Peabody Picture Vocabulary Test. Third Edition. Circle Pines, MN: American Guidance Service.

Heim, I. 1982. The Semantics of Definite and Indefinite Noun Phrases. Ph.D. Dissertation, MIT.

Janke, V. \& Perovic, A. 2015. Intact grammar in HFA? Evidence from control and binding. Lingua 164: 68-86.

Keller, F. \& D. Alexopoulou. 2001. Phonology competes with syntax: Experimental Evidence for the Interaction of Word Order and Accent Placement in the Realization of Information Structure. Cognition 79: 301-372.

Landa, R. 2000. Social language use in Asperger syndrome and high-functioning autism. In Asperger syndrome, A. Klim, F, Volkmar \& S. Sparrow (eds), 125-155. New York: Guilford Press.

Marinis, T., Terzi, A., Kotsopoulou, A. \& Francis, K. 2013. Pragmatic abilities of highfunctioning Greek-speaking children with autism. Psychology 20: 321-337.

Mavrogiorgos, M. 2010. Clitics in Greek. A minimalist account of proclisis and enclisis. Amsterdam: John Benjamins.

Perovic, A. 2006. Syntactic deficit in Down syndrome: more evidence for the modular organization of language. Lingua 116: 1616-1630.

Perovic, A., Modyanova, N. \& Wexler, K. 2013a. Comprehension of reflexive and personal pronouns in children with autism: a syntactic or pragmatic deficit? Applied Psycholinguistics, 34, 813-835. 
Perovic, A., Modyanova, N. \& Wexler, K. 2013b. Comparison of grammar in neurodevelopmental disorders: The case of binding in Williams syndrome and autism with and without language impairment. Language Acquisition, 20, 133-154.

Rizzi, L. 1997. The fine structure of the left periphery. In Elements of Grammar, L. Haegeman (ed), 281-337. Dordrecht: Kluwer Academic Publishers.

Roberts, J. A., Rice, M. L. \& Tager-Flusberg, H. 2004. Tense marking in children with autism. Applied Psycholinguistics, 25: 429-448.

Simos, P.G., Sideridis, G.D., Protopapas, A. \& Mouzaki, A. 2011. Psychometric Evaluation of a Receptive Vocabulary Test for Greek Elementary Students. Assessment for Effective Intervention, 37: 34-49.

Stavrakaki, S. \& Tsimpli, I.M. 2000. Diagnostic Verbal IQ Test for Greek preschool and school age children: standardization, statistical analysis, psychometric properties. In Proceedings of the 8th Symposium of the Panhellenic Association of Logopedists, 95106. Athens: Ellinika Grammata.

Surian, L., Baron-Cohen, S. \& van der Lely, H. K. J. 1996). Are children with autism deaf to Gricean maxims? Cognitive Neuropsychiatry, 1: 55-71.

Tager-Flusberg, H., Paul, R. \& Lord, C. 2005. Language and communication in autism. In Handbook of autism and developmental disorders: Diagnosis, development, neurobiology, and behaviour [ $3^{\text {rd }}$ edition], F. R. Volkmar, R. Paul,A. Klin \& D. J. Cohen (eds), 335-364. Hoboken, New Jersey: John Wiley \& Sons, Inc.

Tager-Flusberg, H. 2000. Language and understanding minds: connections in autism. In Understanding other minds: Perspectives from developmental cognitive neuroscience, S. Baron-Cohen, H. Tager-Flusberg \& D. Cohen (eds), 124-149. Oxford: Oxford University Press. 
Terzi, A., Marinis, T. \& Francis, K. 2015. The interface of syntax with pragmatics and prosody in children with Autism Spectrum Disorders (under review).

Terzi, A., Marinis, T., Francis, K. \& Kotsopoulou, A. 2014. Grammatical Abilities of GreekSpeaking Children with Autism. Language Acquisition, 21: 4-44.

Varlokosta, S. 2000. Lack of clitic pronoun distinctions in the acquisition of principle B in child Greek. In Proceedings of the 24th Boston University Conference on LanguageDevelopment, [BUCLD 24], 738-748. Somerville, MA: Cascadilla Press. 